\title{
Relationship among fibre type, myosin ATPase activity and contractile properties
}

\author{
LEO C. MAXWELL ${ }^{1}$, JOHN A. FAULKNER ${ }^{2}$ and \\ RICHARD A. MURPHY ${ }^{3}$ \\ ${ }^{1}$ Department of Physiology, The University of Texas Health Science Center, San Antonio, Texas 78284, U.S.A. \\ ${ }^{2}$ Department of Physiology, The University of Michigan, Ann Arbor, Michigan 48109, U.S.A. \\ ${ }^{3}$ Department of Physiology, The University of Virginia, Charlottesville, Virginia 22901, U.S.A.
}

Received 25 February 1982 and in revised form 18 May 1982

\begin{abstract}
Summary
At least two types of skeletal muscle myosin have been described which differ in ATPase activity and stability in alkaline or acidic media. Differences in ATPase characteristics distinguish Type I and Type II fibres histochemically. In this study, ATPase activity of myosin from muscles of several species with known histochemical and contractile properties has been determined to test the hypothesis that (1) myosin ATPase activity, (2) histochemical determination of fibre types and (3) maximum shortening velocity, all provide equivalent estimates of contractile properties in muscles of mixed fibre types. Maximum shortening velocity appears to be proportional to ATPase activity as expected from previous reports by Barany. However, both myosin ATPase and the maximum shortening velocity exhibit curvilinear relationships to the fraction of cross-sectional area occupied by Type II fibres. Therefore, we reject the hypothesis and conclude that histochemically determined myofibrillar ATPase does not accurately reflect the intrinsic ATPase activity or shortening velocity in muscles of mixed fibre types. Our data are consistent with the presence of more than two myosin isozymes or with a mixture of isozymes within single muscle fibres.
\end{abstract}

\section{Introduction}

The data of Barany (1967) indicate that the speed of contraction of skeletal muscles from a wide range of species correlates with the adenosine triphosphatase (ATPase) activity of myosin purified from the individual muscles. In most species, at least two isoenzymes of skeletal muscle myosin exist and differ in ATPase activity and stability during exposure to alkaline or acidic media (Barany et al., 1965). In a given species, the ATPase activity of myosin from muscles with high contraction velocities is 2-3 times the ATPase activity of myosins isolated from slowly contracting muscles. The ATPase activity of myosin from fast muscles is stable on exposure to alkali, but labile when exposed to acid. In contrast, myosin from slow muscles is alkali labile and acid stable. 
Histochemical incubations for myofibrillar ATPase demonstrate Type I fibres with low ATPase activity, and Type II fibres with high ATPase activity. Exposure to alkaline or acidic media produces characteristic alterations of histochemical ATPase activity patterns (Brooke \& Kaiser, 1970a, b) which are consistent with the biochemical characteristics of slow and fast myosin ATPase activities. Burke et al. (1971) have correlated the contractile and histochemical properties of single motor units in cat gastrocnemius muscles. Their work suggested that there is a biochemical basis and a functional correlate for the histochemical demonstration of two species of myofibrillar ATPase in muscles having mixed fibre types.

Skeletal muscles contain differing proportions of Type I and Type II fibres. This ranges from exclusively Type I for soleus muscles of guinea-pigs (Barnard et al., 1971; Maxwell et al., 1973) and cats (Maxwell et al., 1977) to nearly 100\% Type II fibres for psoas muscles of guinea-pigs (Maxwell et al., 1973), and rabbits (Weeds et al., 1975). It is reasonable to expect that muscles which differ in the proportions of Type I and Type II fibres should have correspondingly different biochemical and contractile properties. If muscles are comprised of fibres having one or the other type of myosin, the ATPase activity of myosin and the shortening velocity of the muscles should be a function of the proportion of cross-sectional area represented by the two types of fibres. The purpose of the investigation reported here was to determine the myosin ATPase activity of muscles which have widely differing proportions of Type I and Type II fibres and different maximum shortening velocities. The data so obtained was used to test the hypothesis that (1) myosin ATPase activity, (2) histochemical determination of fibre types and (3) maximum contraction velocity, all provide equivalent estimates of contractile properties in muscles of mixed fibre types.

\section{Materials and methods}

SPECIMENS

Muscle samples were obtained from the following species of laboratory animals. Guinea-pig: soleus, diaphragm, plantaris and psoas; rabbit: soleus and psoas; dog: extensor digitorum longus (EDL), semitendinosis and tibialis cranialis; rat: soleus, gastrocnemius, plantaris and EDL; and rhesus monkey: soleus, masseter, temporalis and EDL. In most cases, data points for each muscle represent pooled data from three or more animals.

\section{HIST OCHEMISTRY}

Samples of muscle were snap frozen in isopentane cooled by dry ice. 14-20 $\mu \mathrm{m}$, transverse sections were cut in a cryostat at $-20^{\circ} \mathrm{C}$, thawed and air-dried. Myofibrillar ATPase activity was demonstrated by incubation for $20 \mathrm{~min}$ at $37^{\circ} \mathrm{C}$ in a medium containing: $20 \mathrm{~mm}$ sodium barbital, $100 \mathrm{mM} \mathrm{CaCl}_{2}$ and $1.9 \mathrm{mM} \mathrm{ATP}$ (disodium salt). The $\mathrm{pH}$ was adjusted to 9.4 at $37^{\circ} \mathrm{C}$. Following incubation, the sections were washed three times for 2 min periods in $1 \% \mathrm{CaCl}_{2}$, immersed for $1 \mathrm{~min}$ in each of two changes of $2 \% \mathrm{CoCl}_{2}$, rinsed in four changes of distilled water, and then placed for $1 \mathrm{~min}$ in $1 \%$ ammonium sulphide. The sections were finally dehydrated through a series of ethanols ranging in concentration from $70 \%$ to $100 \%$, cleared in xylene and mounted in Permount. 
Sections were projected at $1000 \times$ magnification and the perimeters of fibres in $25 \mathrm{~cm} \times 40 \mathrm{~cm}$ sample areas outlined on the screen. One hundred to two hundred fibres were analysed per muscle. Fibres on the top and right boundary and in the top two corners were included but fibres crossing the left or bottom boundaries or the bottom corners were excluded. Fibres were classified as Type I (low ATPase activity) or Type II (high ATPase activity). The fibre cross-sectional areas were determined by planimetry, and the proportion of Type II fibres expressed as the total area of Type II fibres divided by the total area of Type I plus Type II fibres.

\section{PURIFICATION OF CONTRACTILE PROTEINS}

\section{Actomyosin}

Muscles were minced and homogenized in 10 volumes of a solution containing: $600 \mathrm{mM} \mathrm{KCl}, 17.5$ mM morpholinopropane sulphuric acid buffer (MOPS; $\mathrm{pH} 7.2-7.3$ at $4^{\circ} \mathrm{C}$ ), $4 \mathrm{mM} \mathrm{MgCl}_{2}, 4 \mathrm{mM}$ EGTA, $0.5 \mathrm{~mm}$ dithiothreitol, and $10 \mathrm{mM} \mathrm{NaHCO}_{3}$. The homogenate was left for $10-12 \mathrm{~h}$ at $4^{\circ} \mathrm{C}$ for extraction of the actomyosin, centrifuged at $16000 \mathrm{~g}$ for $1 \mathrm{~h}$ and the pellet discarded. The supematant was diluted to a $\mathrm{KCl}$ concentration of $100 \mathrm{mM}$ with an ice-cold solution containing 4.4 $\mathrm{mM}$ MOPS ( $\mathrm{pH} \mathrm{7.0)}$ ) plus $0.5 \mathrm{mM}$ dithiothreitol. The precipitate was harvested by centrifugation at $8000 \mathrm{~g}$ for $10 \mathrm{~min}$. The pellet was redissolved in a small volume of $1.0 \mathrm{M} \mathrm{KCl}$, and diluted to 600 $\mathrm{mM} \mathrm{KCl} \mathrm{with} 4.4 \mathrm{mM}$ MOPS plus $0.5 \mathrm{mM}$ dithiothreitol. After centrifugation at $16000 \mathrm{~g}$ for $1 \mathrm{~h}$, the pellet was discarded and the supernatant diluted to $100 \mathrm{mM} \mathrm{KCl}$. The precipitate was collected by centrifugation at $8000 \mathrm{~g}$ for $10 \mathrm{~min}$, washed three times with a solution containing $100 \mathrm{mM} \mathrm{KCl}$, 4.4 mM MOPS ( $\mathrm{pH} \mathrm{7.0),} \mathrm{and} 0.5 \mathrm{~mm}$ dithiothreitol; and finally suspended in that solution at a final concentration of approximately $3 \mathrm{mg}$ protein $/ \mathrm{ml}$. Protein concentration was determined by the Biuret reaction (Layne, 1957).

\section{Myosin}

Muscles were quickly homogenized in a solution containing $300 \mathrm{mM} \mathrm{KCl}, 100 \mathrm{mM} \mathrm{KH}_{2} \mathrm{PO}_{4}, 50$ $\mathrm{mM} \mathrm{K}_{2} \mathrm{HPO}_{4}, 1 \mathrm{mM}$ EDTA, $0.1 \mathrm{mM}$ dithiothreitol and $1 \mathrm{mM} \mathrm{ATP}$; and allowed to extract for 5-10 $\mathrm{min}$. The $10 \mathrm{~min}$ extracts contained substantial amounts of actin. Reduction of the extraction time to $5 \mathrm{~min}$ gave final yields of $8.19 \pm 0.54 \mathrm{mg}$ myosin $/ \mathrm{g}$ muscle with only traces of actin or other contaminants visible in SDS polyacrylamide gels. The homogenate was filtered through cheesecloth, centrifuged at $7700 \mathrm{~g}$ for $15 \mathrm{~min}$, and the supernatant diluted with five volumes of a solution containing $1 \mathrm{mM}$ EDTA plus $0.1 \mathrm{mM}$ dithiothreitol. After standing at $0^{\circ} \mathrm{C}$ for $1 \mathrm{~h}$, the precipitate was harvested by centrifugation. The pellet was dissolved in $3.0 \mathrm{M} \mathrm{KCl}$, with subsequent additions to give a solution containing $500 \mathrm{mM} \mathrm{KCl}, 20 \mathrm{~mm}$ sodium pyrophosphate, $10 \mathrm{mM} \mathrm{MgCl}_{2}, 10 \mathrm{mM} \mathrm{ATP}$ and $0.1 \mathrm{~mm}$ dithiothreitol. The $\mathrm{pH}$ was adjusted as required to 7.0 and the solution was centrifuged at $161000 \mathrm{~g}$ in a Beckman $45 \mathrm{Ti}$ rotor for $90 \mathrm{~min}$. The supernatant was dialysed overnight against three changes of $20 \mathrm{mM} \mathrm{KCl}$ and $1 \mathrm{mM}$ EDTA ( $\mathrm{pH} \mathrm{7.0)}$ ). The precipitated protein was collected by centrifugation at $7700 \mathrm{~g}$ for $20 \mathrm{~min}$, dissolved in $1.0 \mathrm{M} \mathrm{KCl}$, diluted with ice-cold water to $0.5 \mathrm{M} \mathrm{KCl}$ and dithiothreitol added to $0.1 \mathrm{mM}$. After centrifugation at $48000 \mathrm{~g}$ for $2 \mathrm{~h}$, the supernatant was diluted six-fold with ice-cold water and $0.1 \mathrm{mM}$ dithiothreitol was added. The precipitated myosin was harvested by centrifugation at $10000 \mathrm{~g}$ for $10 \mathrm{~min}$, dissolved in $1.0 \mathrm{M} \mathrm{KCl}$, diluted with water to $0.5 \mathrm{M} \mathrm{KCl}$ and dialysed overnight against $0.5 \mathrm{M} \mathrm{KCl}$ and $0.1 \mathrm{mM}$ dithiothreitol. Protein concentration was determined by a micro-Kjeldahl determination assuming a nitrogen content of $16 \%$, and was then adjusted to $1 \mathrm{mg}$ protein/ml.

\section{ELECTROPHORESIS}

An aliquot of the purified myosin preparation was dialysed against distilled water and then denatured at $45^{\circ} \mathrm{C}$ for $15 \mathrm{~min}$ in a solution containing $1 \mathrm{mg}$ myosin/ml, $1 \mathrm{~g} / 100 \mathrm{ml}$ sodium 
dodecyl sulphate (SDS), $5 \mathrm{~g} / 100 \mathrm{ml} \mathrm{D}$-glucose, $10 \mathrm{mM}$ Tris ( $\mathrm{pH} 8.0$ ), $1 \mathrm{mM}$ EDTA, $40 \mathrm{mM}$ dithiothreitol and $0.001 \%$ Pyronine $\mathrm{Y}$ tracking dye. Twenty to $50 \mu 1$ of sample containing $10-50$ $\mu \mathrm{g}$ protein were then subjected to electrophoresis on $5.6 \%$ polyacrylamide gels, stained, and destained as described previously (Cohen \& Murphy, 1978). Gels were scanned with an integrating densitometer (Helena Laboratories Quick Scan Jr) modified with high resolution optics.

\section{ATPASE ASSAYS}

ATPase activities of the contractile proteins were determined from the time course of inorganic phosphate release. The reaction mixture for the actomyosin assay contained: $0.3 \mathrm{mg}$ actomyosin/ml, $17.5 \mathrm{mM}$ MOPS ( $\mathrm{pH} 7.0$ at $25^{\circ} \mathrm{C}$, buffering value $-10 \mathrm{mM} \mathrm{H}^{+} / \mathrm{pH}$ unit), $5 \mathrm{mM}$ $\mathrm{MgCl}_{2}, 5 \mathrm{mM} \mathrm{ATP}, 0.1 \mathrm{mM} \mathrm{CaCl}_{2}$, and sufficient $\mathrm{KCl}$ to adjust total ionic strength to 0.1 . Reactions were initiated by addition of ATP at $25^{\circ} \mathrm{C}$. Aliquots were taken at intervals from 1 to $12 \mathrm{~min}$ and denatured in an equal volume of ice-cold $5 \%$ trichloroacetic acid, vortexed and filtered through Whatman No. 1 paper. Samples of the filtrate were analysed for inorganic phosphate using the procedure of Rockstein \& Herron (1951). Activities were calculated from the linear portion of the time course and expressed as $\mu \mathrm{mol}$ phosphate released $/ \mathrm{mg}$ protein $/ \mathrm{min}$.

Myosin ATPase activity was estimated at $25^{\circ} \mathrm{C}$ in a medium containing $0.05-0.1 \mathrm{mg}$ myosin/ $/ \mathrm{ml}$, $17.5 \mathrm{~mm}$ MOPS ( $\mathrm{pH} 7.0$ ), $4 \mathrm{mM} \mathrm{CaCl}_{2}, 4 \mathrm{mM} \mathrm{ATP}$ and sufficient $\mathrm{KCl}$ to adjust the ionic strength to 0.1 . Reactions were initiated by addition of ATP and samples taken at intervals from 1 to 16 min

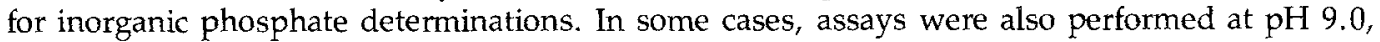
$25^{\circ} \mathrm{C}$, using $0.04 \mathrm{mg}$ myosin/ $/ \mathrm{ml}, 9 \mathrm{mM} \mathrm{CaCl}_{2}, 9 \mathrm{mM} \mathrm{ATP}, 40 \mathrm{mM}$ Tris and $\mathrm{KCl}$ to produce ionic strength of 0.1 .

\section{Results}

\section{Histochemical composition}

The skeletal muscles in this study contain very different proportions of fibre types. The fibre composition of a muscle sample can be expressed either as a proportion of the total number of fibres, or as a proportion of total fibre area which is represented by a given fibre type. In this report, unless otherwise specified, composition is expressed as a proportion of total fibre area. The area proportion of Type II fibres ranges from $0 \%$ for soleus muscle of guinea-pigs to $99 \%$ for psoas muscles of guinea-pigs.

\section{ATPase activities versus composition}

Our initial experiment, in which actomyosin was isolated from rabbit and guinea-pig muscles, yielded an unexpected curvilinear relationship between actomyosin ATPase activity (at $\mathrm{pH}$ 7.0) and the percentage area occupied by Type II fibres (Fig. 1). Since this curvilinear plot could represent a peculiarity of actomyosin preparations, or could arise from unrecognized factors influencing the actin-activated ATPase activity, we repeated the experiment with myosin purified from muscles of guinea-pigs, rats, dogs and rhesus monkeys. A similar curvilinear plot was obtained (Fig. 2). To test whether this relationship might in some way result from the alkaline conditions under which the histochemical myofibrillar ATPase activity is performed, we repeated some assays with the purified myosins at pH 9.0. Again, a curvilinear relationship was observed (Fig. 3). 
Fibre type and myosin ATPase

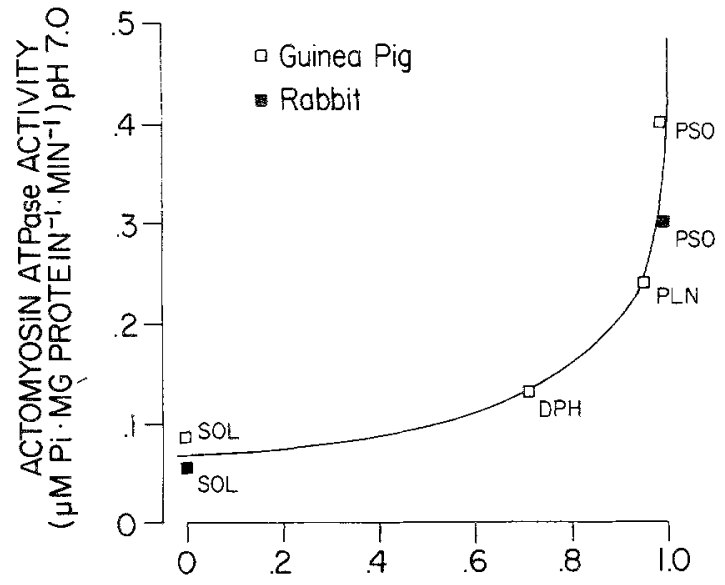

TYPE II FIBRE AREA/TOTAL FIBRE AREA

Fig. 1. Actomyosin ATPase activity plotted as a function of the proportion of area occupied by Type II fibres.

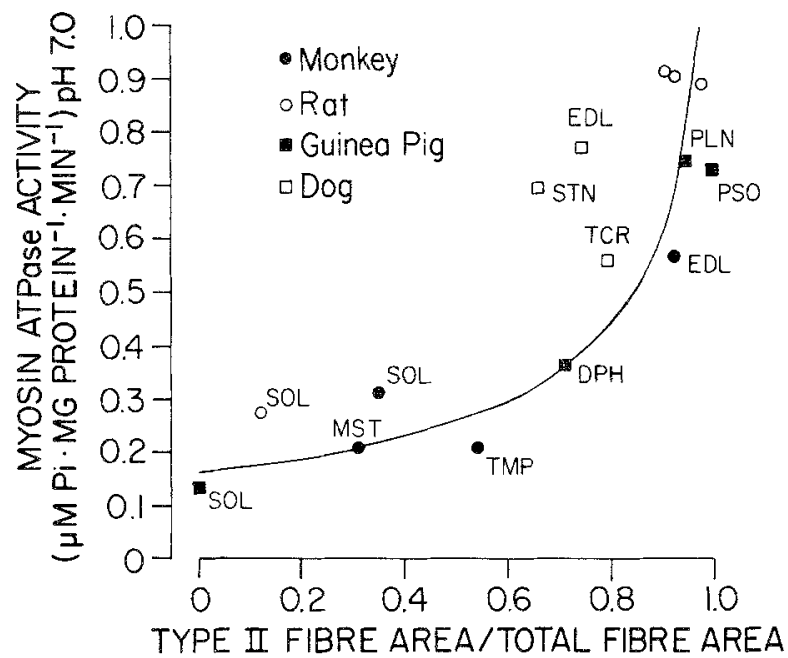

Fig. 2. Myosin ATPase activity at $\mathrm{pH} 7.0$ plotted as a function of the proportion of area occupied by Type II fibres.

Yield of purified myosin

Differential extraction or selective purification of one myosin isozyme could contribute to a non-linear relationship as seen in Figs. 1-3. This type of artifact would be evident as a trend in protein yields as the Type II fibre content increased. The myosin yield varied from 5.5 to $11.7 \mathrm{mg}$ per gram wet weight of muscle. However, there was no relationship between myosin yield and histochemical composition. For example, we obtained $10 \mathrm{mg}$ myosin/g of rat soleus muscle (15\% Type II) and $9 \mathrm{mg}$ myosin/g of rat 


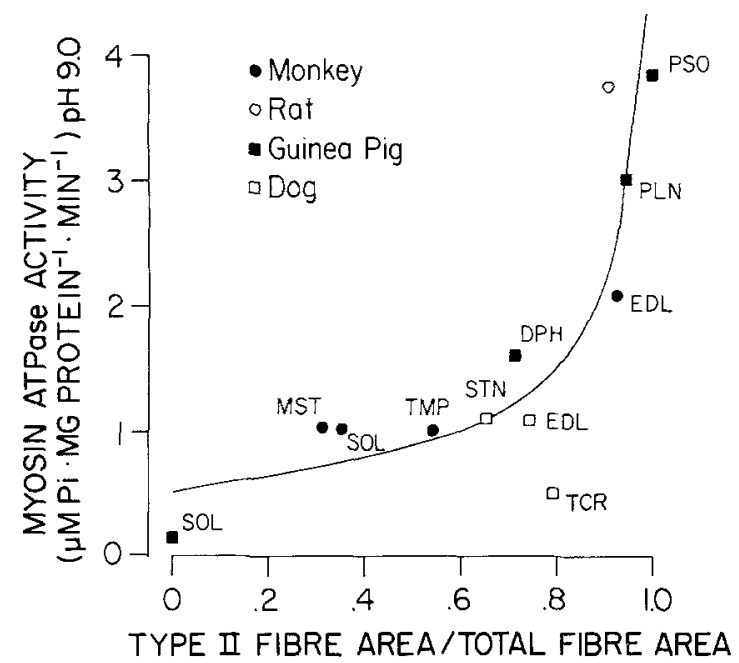

Fig. 3. Myosin ATPase activity at $\mathrm{pH} 9.0$ plotted as a function of the proportion of area occupied by Type II fibres.

plantaris muscle (85\% Type II). Nor was there a relationship between relative yield and muscle sample weight. Similar yields were obtained per gram of muscle from $400 \mathrm{mg}$ of rat soleus muscle and from $7 \mathrm{~g}$ of monkey soleus muscle.

Mixing experiments

Interaction between myosin isoenzymes could cause a mixture of myosins to exhibit ATPase activity less than that which would be predicted from the sum of the specific

\section{MIXING EXPERIMENTS}

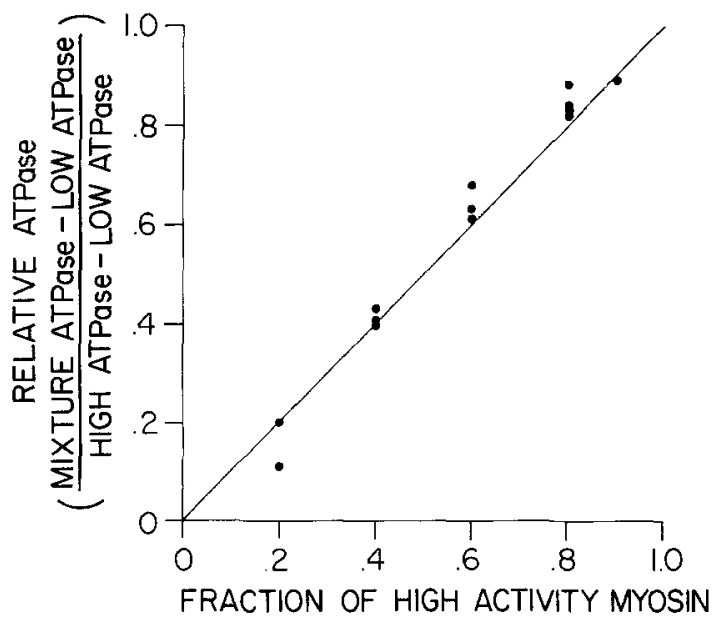

Fig. 4. ATPase activity of mixtures of high and low activity myosins plotted as a function of the fraction of the high activity myosin in the mixture. 
activity times mixture fraction for each isozyme. This possibility was tested in four series of assays using mixtures of a low activity myosin with a high activity myosin (Fig. 4). The mixtures were of myosins from the masseter and the EDL, or temporalis and EDL of rhesus monkeys; and from heart and plantaris, or soleus and psoas of guinea pigs. No cross-species mixing experiments were done. Relative activity was calculated as the ATPase measured for the mixture minus ATPase of the low activity myosin, divided by the difference in ATPase between the high and low activity myosins. This resulted in expression of activity on a scale of $0-1$, where 0 represents the low activity myosin and 1 the high activity myosin. Thus, data from all mixing experiments could be compared even though the absolute ATPase activities varied considerably with myosins from different species. When relative ATPase was plotted as a function of the proportion of high activity myosin in the mixture, a linear relationship resulted which did not differ significantly from a line of identity (Fig. 4).

\section{Relationship of maximum shortening velocity to histochemical fibre type}

We have compiled a substantial list of muscles for which both contractile and histochemical data are available either within one study or from independent studies (Table 1). For many muscles of known histochemical composition, either maximum shortening velocity $\left(V_{\max }\right)$ or the time to peak isometric tension (TPT) has been determined. While TPT is a function both of intrinsic contractile speed and of the duration of the active state, Close $(1965,1972)$ has shown that a wide range of muscles exhibit a linear relationship between the inverse of TPT and $V_{\max }$. Fourteen data points obtained from Faulkner et al. (1979), Close (1972) and Barany (1967) were used to calculate a least squares regression between $V_{\max }$ and 1/TPT. The regression equation is: $V_{\max }$ (lengths/s) $=1.96+175 /$ TPT (ms), the correlation coefficient is 0.99 and the standard error of estimate is 0.93 . Although some uncertainties are involved, we used this regression to estimate $V_{\max }$ for muscles of known TPT. Fig. 5 summarizes both estimated (open symbols) and measured (closed symbols) values of $V_{\max }$ as a function of histochemical composition for 45 muscles of cats, rats, monkeys, guinea pigs, mice, rabbits and humans. The range of data points based on estimates of $V_{\max }$ from TPT overlaps the range of data points based on measured $V_{\max }$ and a curvilinear relationship is exhibited by either type of data. Since Type II fibres are usually larger than Type I fibres, the curvilinear relationship exhibited between $V_{\max }$ and the proportion of Type II fibres would be even more pronounced if Type II fibres had been expressed as a fraction of total fibre area rather than as a percentage of fibre number. Unfortunately, for many studies, only the data on the number of fibres were available, so this correction could not be applied. 


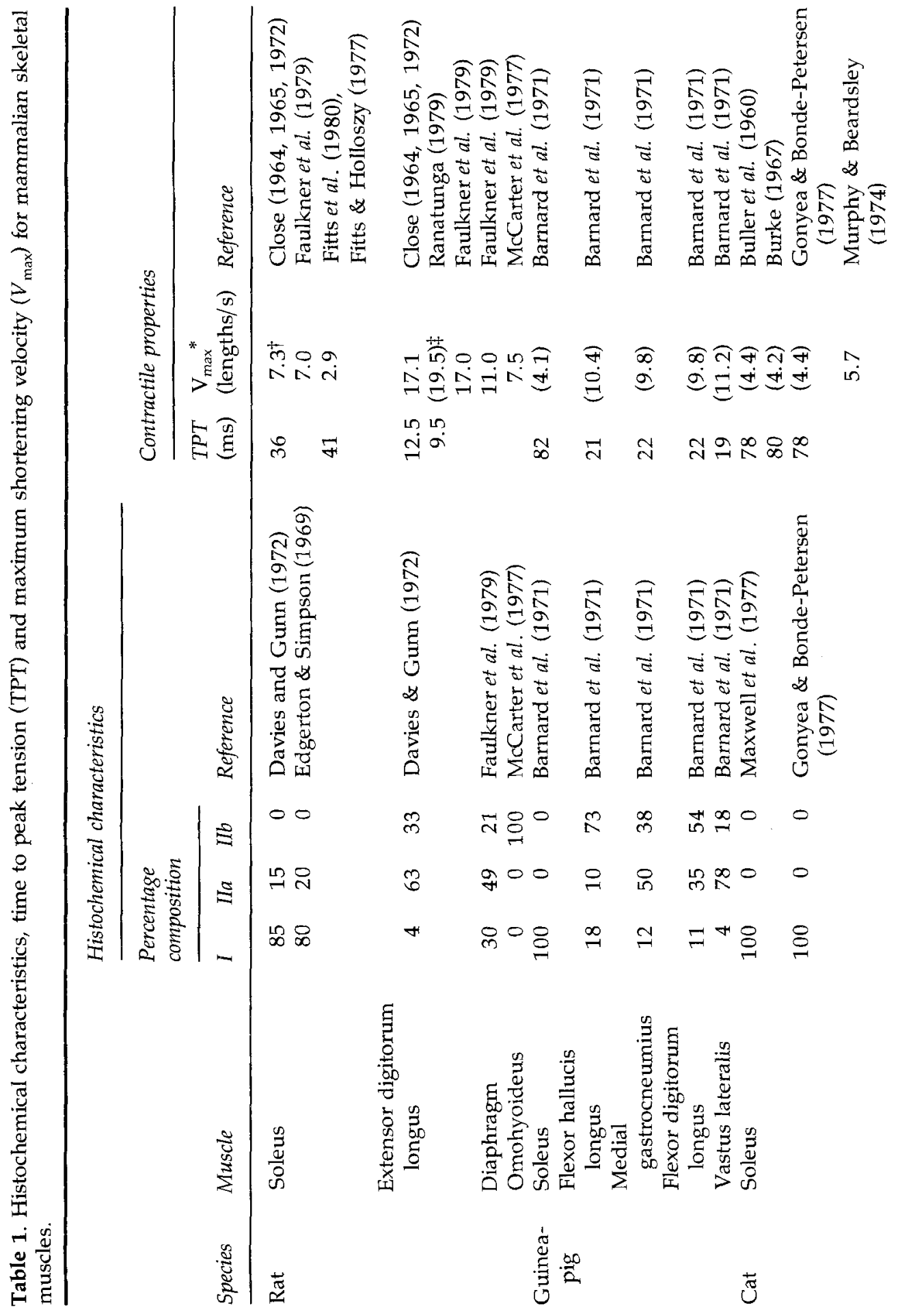




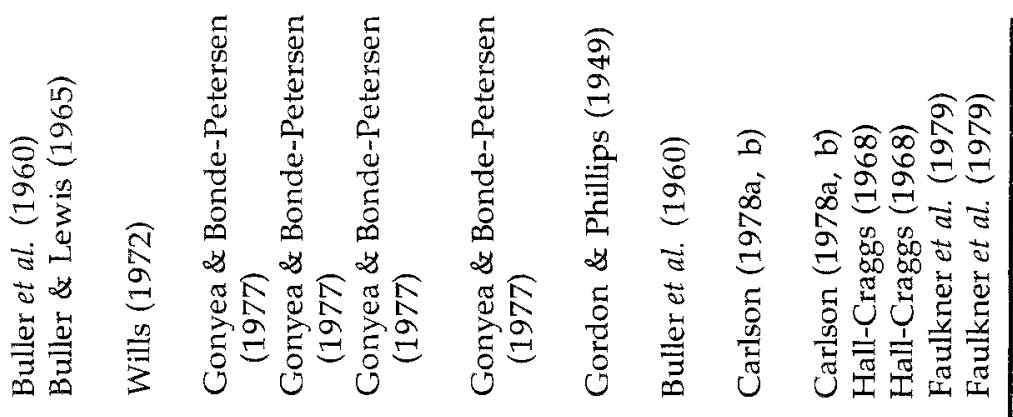

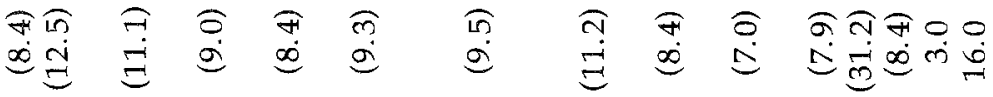

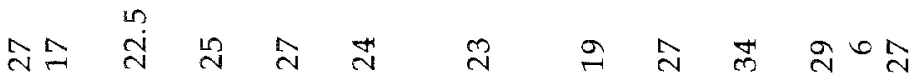

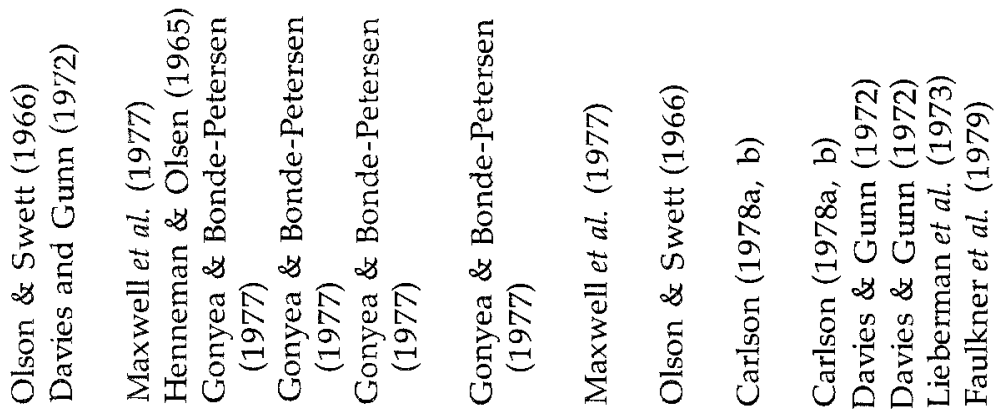

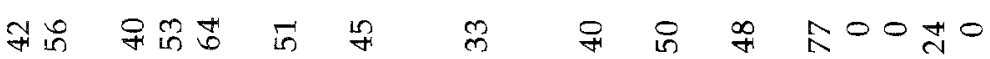

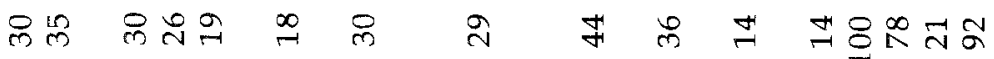

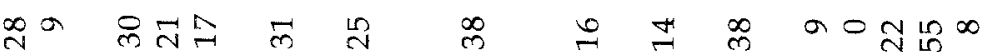

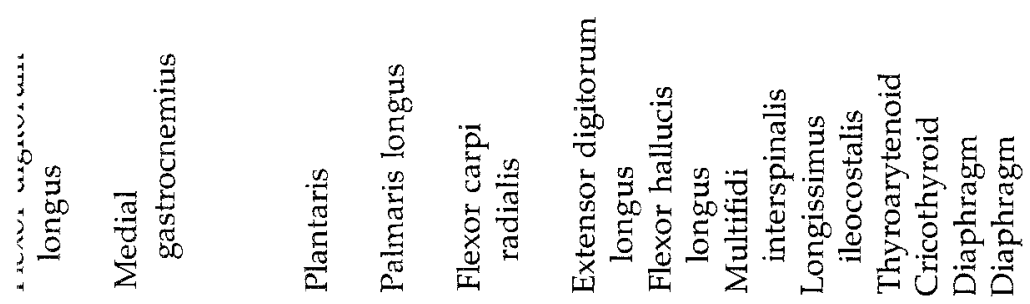

迎 


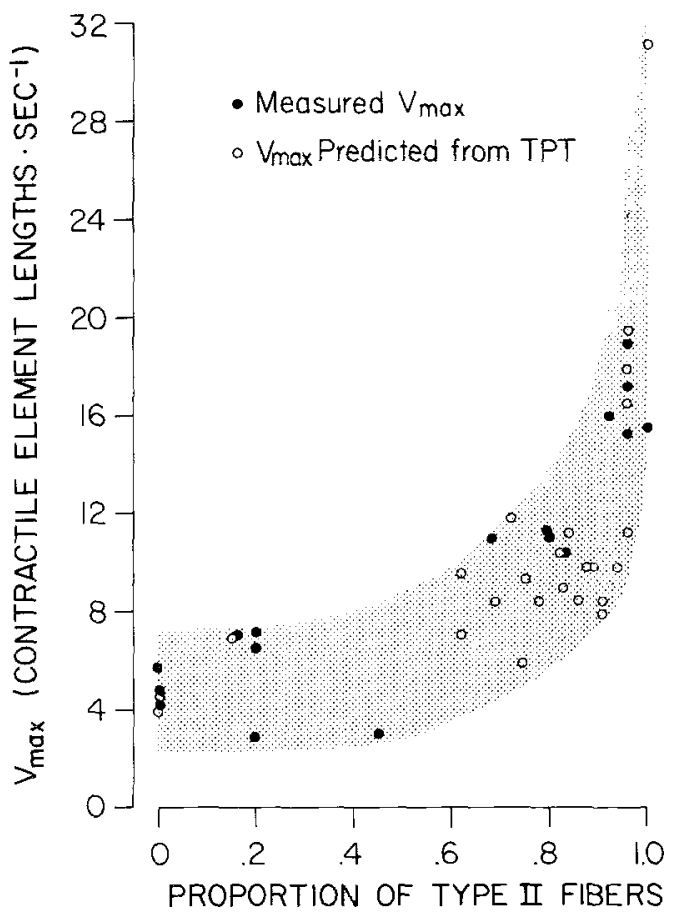

Fig. 5. Maximum shortening velocity of muscles plotted as a function of the proportion of area occupied by Type II fibres.

\section{Discussion}

Neither the ATPase activity of actomyosin nor of myosin at $\mathrm{pH} 7.0$ or $\mathrm{pH} 9.0$ is linearly related to the proportion of cross-sectional area occupied by Type II fibres. Thus our original hypothesis is rejected, and we now consider possible explanations for the non-linear relationships observed. A curvilinear relationship between these variables could arise from systematic errors affecting (1) the estimate of mixed muscle contractile protein ATPase activity, or (2) the histochemical estimation of fibre types and fractional composition of the muscle.

Possible errors in the first category include (1) different cellular myosin concentrations in different fibre types, (2) differential extraction or selective purification of contractile proteins from different fibre types, (3) interactions affecting specific myosin isoenzyme specific ATPase activity, or (4) differences in myosin ATPase activity amongst species.

The length and structure of thick and thin filaments do not differ among vertebrate skeletal muscles or fibre types (Close, 1972). However, differences in contractile protein content between Type I and Type II fibres could result from differences in the relative proportion of fibre cross-sectional areas occupied by myofibrils. However, stereological analysis (Eisenberg \& Kuda, 1974a, b) indicates that myofibrils occupy $82 \%$ of the fibre core in white vastus compared to $87 \%$ for soleus muscle fibres in rats. This difference could not account for the results we have obtained. 
Yields of myosin from various muscles showed no relationship to the histochemical composition of the muscle. Therefore, systematic differences in extraction or purification of myosins from Type I and Type II muscle fibres are not a likely contributing factor to the contractile protein ATPase data.

Interaction between myosins of different intrinsic ATPase activity such that the slower myosin was nearer its optimal state of activation than the faster myosin could result in the slower myosin contributing a greater share of ATPase activity than would be predicted from the fraction of the slow myosin. However, mixtures of myosins of differing ATPase activities yield results predicted from their specific activities and the fraction of each myosin in the mixture. Thus no interactions between myosins were observed. We conclude that errors in the estimation of mixed muscle contractile protein ATPase do not account for the non-linear relationship between contractile protein ATPase activity and histochemical composition.

A curvilinear relationship could result if the ATPase activity of fast myosin in muscles with $>80 \%$ Type II fibres were higher than fast myosin ATPase activity in muscles with $<80 \%$ Type II fibres. Since 'fast' muscles from different species exhibit different maximum shortening velocity and myosin ATPase activities, it is important to consider whether the curvilinear relationship observed is an artifact resulting from the selection of animals and muscles. If some species had both a higher fast myosin ATPase activity and a greater proportion of Type II fibres in limb muscles, the observed relationship could be explained. However, our data do not follow these conditions and we do not consider species difference in fast myosin an adequate explanation of the data. Although the choice of a Type II fibre area/total fibre area ratio of 0.8 is arbitrary, a reasonable linear relationship could be drawn through the data points in Figs. 1-3 for muscles with a ratio $<0.8$, and another linear relationship with steeper slope for muscles with a ratio $>0.8$. Two points are evident for the muscles with a ratio $>0.8$ : (1) the high myosin ATPase activities come from a variety of species (rats, guinea-pigs, rabbits, monkeys), and (2) although there is a suggestion that the myosin ATPase activity for muscles with $>80 \%$ Type II fibres may be inversely related to size, none of the data points fall below a relationship extrapolated from the muscles of rats, guinea-pigs, rabbits and monkeys which have a ratio $<0.8$.

Barany (1967) has demonstrated that the maximum velocity of sarcomere shortening $\left(V_{\max }\right)$ is well correlated with the ATPase activity of myosin extracted from a variety of muscles. This correlation has been extended by the results of other investigators (Close, 1965, 1972). Therefore, for the remainder of this discussion we will assume that maximal velocity of shortening is a linear function of myosin ATPase activity for the muscles studied in the current investigation. The similarity in our current data of the relationship between $V_{\max }$ and the percentage of Type II fibres to the relationship between myosin ATPase and the percentage area occupied by Type II fibres supports this assumption. We conclude that the myosin ATPase results of this study are consistent with available contractile velocity data.

The second type of systematic errors which could produce the observed results arises from the use of histochemical procedures to estimate fractional fibre composition. 
Possible errors in this category include (1) differential swelling or shrinkage effects of the histochemical procedures on the cross-sectional areas of Type I and II fibres, (2) contribution of other ATPase or phosphatases to the histochemical reaction, or (3) failure to detect more than two myosin isoenzymes present in a mixed muscle.

During routine processing of muscle samples for freezing, sectioning and incubations, Type I and Type II fibre areas might be affected differently. If the cross-sectional area of Type II shrank more than Type I fibres or the cross-sectional area of Type I fibres expanded more than Type II fibres, an effect on the relationship of ATPase activity to the proportion of fibre area would result. While it is not possible to rule out a differential effect of processing on the area of Type I and Type II fibres, the preservation of myofibrillar spacing in both types of fibres suggests that the magnitude of differential shrinkage would be insufficient to account for the data.

In the histochemical assay, an ATPase activity not associated with myosin might be revealed in some fibres. This would result in an erroneous classification of fibres with low myofibrillar ATPase as Type II. However, sarcotubular or mitochondrial ATPases are not likely to be demonstrated at the alkaline ( $\mathrm{pH}$ 9.4) conditions used for the myofibrillar ATPase reaction (Gauthier, 1967). Moreover, the sensitivity of myofibrillar ATPase reaction intensity to myofibrillar inhibitors or activators, as well as the block-like pattern of localization of end-product are consistent with a myofibrillar origin of the ATPase activity (Gauthier, 1967).

Myosin ATPase activity in biochemical assays, the myofibrillar ATPase in histochemical assays, or both, might inaccurately reflect the actual intrinsic activity of myosin and the maximum velocity of shortening. Comparison of measurements of myosin ATPase activity, histochemical composition, and maximum velocity of shortening on each of a variety of different muscles permits evaluation of interactions between these three variables and the identification of one which does not accurately predict the other two. Comparison of the histochemical data and myosin ATPase determinations from this study to contractile properties data obtained by us and others suggests that it is the histochemical procedures which are the source of the discrepancy. The data in this report would be explained if the proportion of fibres having myosin with high ATPase activity and fast $V_{\max }$ were overestimated by the histochemical myofibrillar ATPase reaction. There is reason to suspect that this occurs.

It is likely (Robbins et al., 1969) that the histochemical demonstration of myofibrillar ATPase is a threshold reaction such that a certain intrinsic ATPase activity is required for the histochemical demonstration of myofibrillar ATPase activity. This is due to the use of calcium ions as a trapping agent for phosphate in the histochemical assay. A threshold point would be determined when the rate of release is sufficiently greater than the rate of diffusion of phosphate away from the reaction site that the local concentrations of calcium and phosphate exceed their solubility product and form a precipitate. The apparent intensity of reaction would then be a function of ATPase activity for a fibre whose intrinsic ATPase activity exceeds the threshold. If muscle fibres existed as discrete populations with divergent contractile velocities and 
myosin ATPase activities, and the threshold for end-product precipitation occurred at a specific ATPase activity between that of the two populations, then physiological and histochemical classifications would agree.

However, if there is also a maximum intensity of ATPase reaction which can be visually discriminated, fibres classified as Type II on that basis could represent a range of intrinsic myofibrillar ATPase activities and $V_{\text {max }}$. In this case, all fibres whose rate of phosphate production exceeded the requirements for maximal detection of end-product would be classified Type II even if considerable differences in intrinsic ATPase exist. Fig. 6 illustrates how the apparent intensity of the myofibrillar ATPase reaction could inaccurately represent the intrinsic contractile protein ATPase activity. In order for this hypothesis to be an explanation of the curvilinear relationship between percentage area of Type Il fibres and myosin ATPase activity, there would need to be more than two types of myosin in skeletal muscles, a mechanism resulting in a continuum of myosin ATPase activity amongst individual fibres, or both.

Skeletal muscles may contain more than two types of myosin and fibres. There is recent evidence for a specific 'fast red' (Type IIA) as well as a 'fast white' (Type IIB) myosin isozyme (Pierobon-Bormioli et al., 1981). The sensitivity of ATPase activity of Type II fibres to formaldehyde (Guth \& Samaha, 1972; Samaha et al., 1970) or to pre-incubation in acidic media (Brooke \& Kaiser, 1970a,b) is not homogeneous. The myofibrillar ATPase activity of Type Ila fibres is completely inhibited following prior

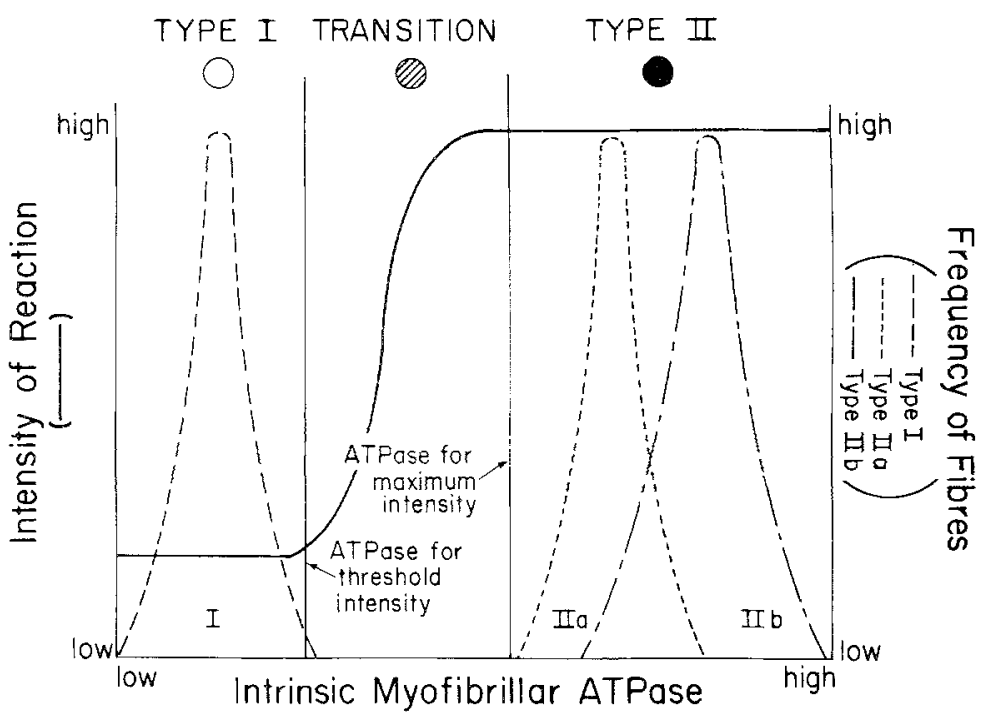

Fig. 6. A hypothetical relationship between the intensity of the histochemical myofibrillar ATPase reaction and the 'intrinsic' myofibrillar ATPase activity. Intrinsic ATPase activities for the threshold of histochemical demonstration and for the maximum histochemical intensity are indicated. Three hypothetical populations of fibres having differing intrinsic ATPase activity are shown and the histochemical appearance schematically indicated. 


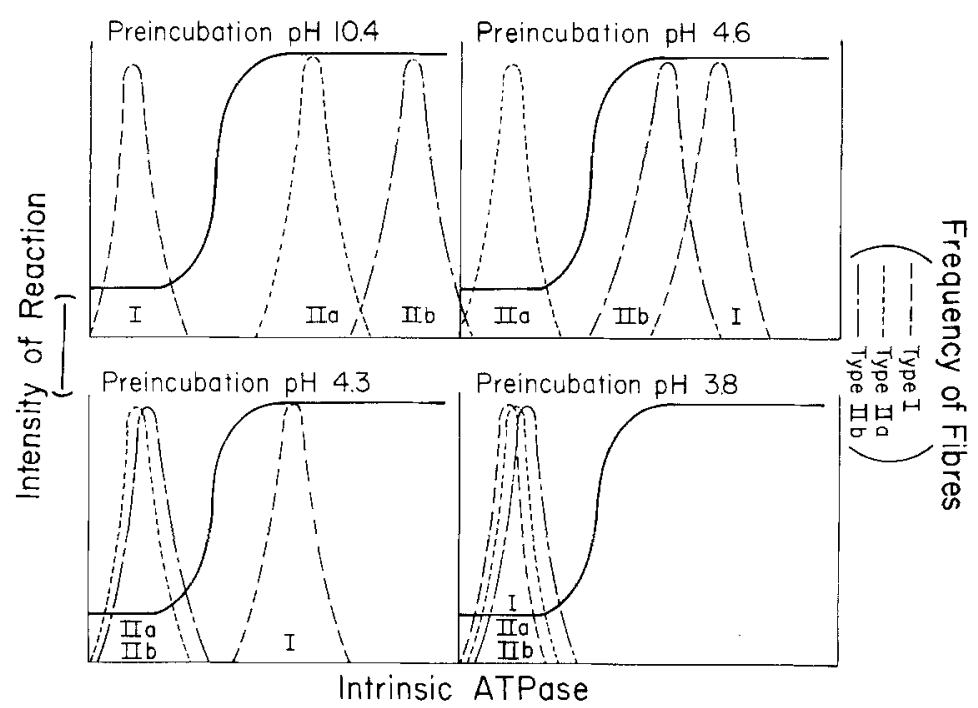

Fig. 7. The behaviour of the three fibre populations from Fig. 6 following pre-incubation at selected $\mathrm{pH}$.

incubation at $\mathrm{pH} 4.5$, whereas Type IIb fibres require prior incubation at $\mathrm{pH} 4.3$ for complete inhibition. Thus, the characteristics of myofibrillar ATPase can be altered to demonstrate at least three intensities of reaction. Fig. 7 shows how the effects of various pre-incubation procedures could affect the intensity of the histochemical reaction by altering the intrinsic ATPase activity. Figs. 6 and 7 are hypothetical but are consistent with histochemical phenomena. If Type Ila fibres had a lower intrinsic ATPase activity than Type IIb fibres, these figures suggest how this difference might fail to be resolved histochemically. Thus, the curvilinear relationship between contractile protein ATPase activity and the percentage of area occupied by Type II fibres could be explained by this hypothesis.

A body of evidence is accumulating which shows that more than a single type of myosin may exist within an individual muscle fibre. Co-existence of myosin isozymes within single fibres has been observed using immunofluorescent techniques in developing skeletal muscles (Gauthier et al., 1978; Pette et al., 1979), the soleus (Gauthier \& Lowey, 1977) and extensor digitorum longus (Pierobon-Bormioli et al., 1981) muscles of adult rats, the anterior tibialis muscles of adult rabbits (Lutz et al., 1979) and in Purkinje fibres in chicken hearts (Sartore et al., 1978). In the rabbit and rat muscles, co-existence of myosin isozymes occurs predominantly in Type Ila fibres (Lutz et al., 1979; Pierobon-Bormioli et al., 1981), and there is a continuum apparent in the relative proportions of each isozyme across the Ila fibre population. Myosin isozymes could exist as independent molecules or as hybrid molecules with both isozymes represented (Pette et al., 1979). In either case, co-existence of myosin isozymes in Type Ila fibres is a mechanism whereby the resultant intrinsic ATPase activity and $V_{\max }$ of 
individual Type II fibres could fit a continuum from low to high ATPase and slow to fast $V_{\max }$ while exhibiting a uniform histochemical expression of myofibrillar ATPase.

The observed curvilinear relationships between contraction velocity or myosin ATPase activity and the proportion of Type II fibres are consistent with either a third myosin isozyme of relatively low ATPase activity or the presence of a mixture of Type I and Type II myosins in some Type II fibres. We know of no direct evidence for either possibility in the muscles we have studied. Nevertheless, these hypotheses may also offer a partial explanation for the recent report by Fitts et al. (1980) that the proportion of Type II fibres increases in muscles of thyrotoxic rats without a coincident increase in $V_{\max }$ or actomyosin ATPase activity.

\section{Acknowledgement}

This research was sponsored by Public Health Service Grant no. NS 17017 from the National Institute of Neurology, Communicative Diseases and Stroke.

\section{References}

BARANY, M. (1967) ATPase activity of myosin correlated with speed of muscle shortening. J. gen. Physiol. 50, 197-216.

BARANY, M. K., BARANY, T., RECKARD, T. \& VOLPE, A. (1965) Myosin of fast and slow muscles of the rabbit. Archs Biochem. Biophys. 109, 185-91.

BARNARD, R. M., EDgerton, V. R., FURAKAWA, T., PETER, J. B. (1971) Histochemical, biochemical and contractile properties of red, white and intermediate fibers. Am. J. Physiol. 220, 410-4.

BROOKE, M. H. \& KAISER, K. K. (1970a) Muscle fiber types: how many and what kind? Arch. Neurol. 23, 369-79.

BROOKE, M. H. \& KAISER, K. K. (1970b) Three 'myosin adenosine triphosphatase' systems: the nature of their $\mathrm{pH}$ lability and sulfhydryl dependence. J. Histochem. Cytochem. 18, 670-2.

BUlLeR, A. J. , ECCLES, J. C. \& ECCLES, R. M. (1960) Differentiation of fast and slow muscles in the cat hind limb. J. Physiol., Lond. 150, 399-416.

BULLER, A. J. \& LEWIS, D. M. (1965) Further observations on the differentiation of skeletal muscles in the kitten hind limb. J. Physiol., Lond. 176, 355-70.

BURKE, R. E. (1967) Motor unit types of cat triceps surae muscle J. Physiol., Lond. 193, 141-60.

BURKE, R. E., LEVINE, P. N., ZAJAC, F. E. III, TSAIRIS, P. \& ENGEL, W. K. (1971) Mammalian motor units: physiological correlates of three types in cat gastronemius. Science 174, 709-12.

CARLSON, H. (1978a) Morphology and contraction properties of cat lumbar back muscles. Acta physiol. scand. 103, 180-97.

CARLSON, H. (1978b) Histochemical fiber composition of lumbar back muscles in the cat. Acta physiol. scand. 103, 198-209.

CLOSE, R. I. (1964) Dynamic properties of fast and slow skeletal muscles of the rat during development. J. Physiol, Lond. 173, 74-95.

CLOSE, R. I. (1965) The relation between intrinsic speed of shortening and duration of the active state of muscle. J. Physiol., Lond. 180, 542-59.

CLOSE, R. I. (1972) Dynamic properties of mammalian skeletal muscles. Physiol. Rev. 52, 129-97. 
COHEN, D. M. \& MURPHY, R. A. (1978) Differences in cellular contractile protein contents among porcine smooth muscles. Evidence for variation in the contractile system. J. gen. Physiol. 72, 369-80.

DAVIES, A. S. \& DUNN, H. M. (1972) Histochemical fiber types in the mammalian diaphragm. J. Anat. 112, 41-60.

EDGERTON, V.R. \& SIMPSON, D. R. (1969) The intermediate fiber of rats and guinea pigs. J. Histochem. Cytochem. 17, 828-38.

EISENBERG, B. R. \& KUDA, A. M. (1974a) Stereological analysis of mammalian skeletal muscle I. Soleus muscle of the adult guinea pig. J. Cell Biol. 60, 732-54.

EISENBERG, B. R. \& KUDA, A. M. (1974b) Stereological analysis of mammalian skeletal muscle II. White vastus muscle of the adult guinea pig. J. Cell Biol. 60, 755-65.

FAULKNER, J. A., MAXWELL, L. C., RUFF, J. L. \& WhITE, T. P. (1979) The diaphragm as a muscle. Contractile properties. Ann. Rev. Respir. Disease 119, 89-92.

FITTS, R. H. \& HOLLOSZY, J. O. (1977) Contractile properties of rat soleus muscle: effects of training and fatigue. Am. J. Physiol. Cell Physiol. 2, C86-C91.

FITTS, R. H., WINDER, W. W., BROOKE, M. H., KAISER, K. K. \& HOLLOSZY, J. O. (1980) Contractile, biochemical and histochemical properties of thyrotoxic rat soleus muscle. Am. J. Physiol. 238, C15-C20.

GAUTHER, G. F. (1967) On the localization of sarcotubular ATPase activity in mammalian skeletal muscle. Histochemie 11, 97-111.

GAUTHIER, G. F. \& LOWEY, S. (1977) Polymorphism of myosin among skeletal muscle fiber types. J. Cell Biol. 74, 760-79.

GAUTHIER, G. F., LOWEY, S. \& HOBBS, A. W. (1978) Fast and slow myosin in developing muscle fibres. Nature, Lond. 274, 25-9.

GAUTHIER, G. F. \& LOWEY, S. (1979) Distribution of myosin isoenzymes among skeletal muscle fiber types. J. Cell Biol. 81, 10-25.

GONYEA, W. \& BONDE-PETERSEN, F. (1977) Contraction properties and fiber types of some forelimb and hind limb muscles in the cat. Expl Neurol. 57, 637-44.

GORDON, G. \& PHILliPS, C. G. (1949) Slow and rapid components in a flexor muscle. J. Physiol. $110,6 \mathrm{P}$.

GUTH, L., \& SAMAHA, F. J. (1972) Erroneous interpretations which may result from application of the 'myofibrillar ATPase' histochemical procedure to developing muscle. Expl Neurol. 34, 465-76.

HALL-CRAGGS, E. C. B. (1968) The contraction times and enzyme activity of two rabbit laryngeal muscles. J. Anat. 102, 241-55.

HENNEMAN, E. \& OLSON, C, B. (1965) Relations between structure and function in the design of skeletal muscle. J. Neurophysiol. 28, 581-98.

LAYNE, E. (1957) Spectrophotometric and turbidimetric methods for measuring proteins. Meth. Enzym. 3, 447-54.

Lieberman, D. A., faulkner, J. A., CRAig, A. B. JR \& MAXWell, L. C. (1973) Performance and histochemical composition of guinea pig and human diaphragm. J. appl. Physiol. 34, 233-7.

LUTZ, H., WEBER, H. \& JENNY, E. (1979) Fast and slow myosin within single skeletal muscle fibers of adult rabbits. Nature, Lond. 281, 142-4.

MAXWEll, L. C., BARClay, J. K., MOHRMAN, D. E. \& FAulkner, J. A. (1977) Physiological characteristics of skeletal muscles of dogs and cats. Am. J. Physiol. 233, C14-8.

MAXWELL, L. C., FAULKNER, J. A. \& LIEBERMAN, D. A. (1973) Histochemical manifestations of age and endurance training in skeletal muscle fibers: Am. J. Physiol. 344, 356-61.

MCCARTER, R. D., RADICKE, D. \& YU, B. P. (1977) A model preparation for studying fast mammalian skeletal muscles. Proc. Soc. exp. Biol. Med. 156, 40-5. 
MURPHY, R. A. \& BEARDSLEY, A. C. (1974) Mechanical properties of the cat soleus muscle in situ. Am. J. Physiol. 227, 1008-13.

OLSON, C. B. \& SWETT, C. P. (1966) A functional and histochemical characterization of motor units in a heterogenous muscle (flexor digitorum longus) of the cat. J. Comp. Neurol. 128, 475-97.

PETTE, D., VRBOVA, G. \& WHALEN, R. C. (1979) Independent development of contractile properties and myosin light chains in embryonic chick fast and slow muscle. Pflugers Arch. 378, 251-7.

PIEROBON-BORMIOLI, S., SARTORE, S., DALlA LIBERA, L., VITADELlO, M. \& SCHIAFFINO, S. (1981) 'Fast' isomyosins and fiber types in mammalian skeletal muscle. J. Histochem. Cytochem. 29, 1179-88.

RANATUNGA, K. W. (1979) Potentiation of the isometric twitch and mechanism of tension recruitment in mammalian skeletal muscle. Expl Neurol. 63, 266-76.

ROBBINS, N., KARPATI, G. \& ENGEL, W. K. (1969) Histochemical and contractile properties in the cross innervated guinea pig soleus muscle. Arch. Neurol. 20, 318-26.

ROCKSTEIN, M. \& HERRON, P. W. (1951) Colorimetric determination of inorganic phosphate in microgram quantities. Analyt. Chem. 23, 1500-1.

Samaha, F. J., GUth, L. \& Albers, R. W. (1970) Phenotypic differences between the actomyosin ATPase of the three fiber types of mammalian skeletal muscle. Expl Neurol. 26, $120-5$.

SARTORE, S., PIEROBON-BORMIOLI, S. \& SCHIAFFINO, S. (1978) Immunochemical evidence of myosin polymorphism in the chicken heart. Nature, Lond. 274, 82-3.

WEEDS, A. G., HALL, R. \& SPURWAY, N. C. S. (1975) Characterization of myosin light chains from histochemically identified fibers of rabbit psoas muscle. FEBS Lett. 49, 320-4.

WILlS, J. H. (1972) Speed of responses of various muscles of cats. Am. J. Physiol. 136, 623-8. 